\title{
Corruption and Growth in a Dynamic General Equilibrium Model
}

\author{
Prof. Wei-Bin Zhang \\ Ritsumeikan Asia Pacific University, Japan
}

\begin{abstract}
This study introduces some new perspectives of bureaucratic corruption into the dynamic general equilibrium theory recently proposed by Zhang. The main concern of our study is the role of corruption on economic growth and income and wealth distribution between the officials and workers. The economy is composed of the industrial sector and public sector. The population is classified into officials and workers. Corruption takes places through many channels. Officials take brides from producers and households. The model describes dynamic interactions of growth, corruption with fixed tax rate and corruption rates. We simulate the model to demonstrate existence of equilibrium and motion of the dynamic system. We also examine effects of changes in different parameters on the motion of the economic system.
\end{abstract}

Keywords: corruption rate on wealth; corruption rate on wage income; corruption rate on output; economic growth; endogenous labor supply;

JEL Classification: O41; D3; E2

\section{Introduction}

Corruption may occur at any part of society. As Lui (1996) pointed, corruption exists in all countries. Economic causes and consequences of corruption are important and difficult issues. There are many theoretical studies on corruption and economic growth (Becker, 1968; Rose-Ackerman, 1999; Shi and Temzelides, 2004; Acemoglu and Verdier, 1998; Dzhumashev, 2014; D'Agostino, etal. 2016). There are also many empirical studies on corruption and economic growth (e.g., Mauro, 1995, 1998; Ehrlich and Lui, 1999; Del Monte and Papagni, 2001; Rivera-Batiz, 2001; Glaeser and Saks, 2006; Swaleheen and Stansel, 2007; Teles, 2007; Gyimah-Brempong, 2002; Chea, 2015). The literature is too vast to be properly reviewed here. Different researchers emphasize different aspects of corruption. There is no general convergent conclusion on the role of corruption on economic growth. Chea (2015: 187) reveals "From the theoretical background and empirical evidence from various studies spread in various countries in the world using different methods over the years, there are mostly negative findings of economic growth. Nevertheless, there are also positive findings found on the effects of corruption on economic growth." For instance, Leff (1964) pointed out possible positive effects of corruption on economic growth. Huntington (1968) holds that the "efficient corruption", for instance, in the form of bribery, may enable firms to get works completed in a political economic environment plagued by bureaucratic complexity. Corruption may smooth operations so that the efficiency of the whole system is enhanced (Mo, 2001). Myrdal (1968) pointed out that corruption causes economic inefficiency as officials may delay permissions of projects in order to get bribes. According to the recent review by Dzhumashev (2014: 203), "the existing literature lacks a more general approach for interpreting the role of governance, the size government, and the level of development in the relationship between corruption and growth." As corruption may exist everywhere in society, it is necessary to study corrupt behavior within a dynamic equilibrium framework.

We analyze issues related to corruption and growth in a two-sector two-group economy. The dynamic general equilibrium framework enables us to analyze different aspects of corruption. We introduce a public sector to the neoclassical growth model. Public goods is important for understanding modern economies. (Barro, 1990; and Turnovsky, 2000, 2004). We study the dynamic relationship between government's spending, officials' wage and wealth, and corruption. Different from the traditional 
models with the Ramsey utility (e.g., Barro and Sala-i-Martin, 1992; Futagami et al., 1993; Glomm and Ravikumar, 1997; Agénor, 2011; Baier and Glomm, 2001; Palivos et al., 2003; Greiner, 2007; Hu et al., 2008; Kamiguchi and Tamai, 2011; and Chen and Guo, 2014), this study applies Zhang's utility function (Zhang, 1993, 2009). We examine a dynamic interdependence between labor supply and economic growth with taxation on the industrial sector. The tax income is spent on supplying public goods. The main concern of this study is the impact of bureaucratic corruption on economic growth. According to Dzhumashev (2014:202): "When the public and private sectors interact, bureaucrats may abuse their public position for private gains by accepting bribes or even actively extorting them. This behavior is defined as an act of bureaucratic corruption." This study is an extension of the growth models with public goods proposed by Zhang (2010). The main differences of this paper from Zhang's previous studies are that this study classifies the population into the workers and the officials and takes account of corruption. It should be noted that as far as how corruption is introduced into the neoclassical growth model, this study is influenced by Lin and Zhang (2009). As Lin and Zhang (2009: 69), "Most prior theoretical studies have been devoted to understanding the micro-foundation of determination of corruption and the implications for efficiency. Relatively few attempts have been made to analyze corruption with a dynamic general equilibrium framework." Rather than the traditional two-periodic growth model accepted by Lin and Zhang, this study applies Zhang's analytical framework. We model behavior of the officials and workers with Zhang's utility function and concept of disposable income. The rest of the paper is organized as follows. Section 2 introduces the basic model with wealth accumulation and corruption within a two-sector two-group framework. In section 3 we study dynamic properties of the model. Section 4 simulates the motion of the economic system and demonstrates effects of changes in some parameters on the economic system. Section 5 concludes the study.

\section{The basic model}

We consider that the economy is composed of one industrial sector and one public sector. There is a single good, called industrial good, in the economy and the price of the industrial good is unity. Capital depreciates at a fixed rate, $\delta_{k}$. Most aspects of the industrial sector are similar to the standard one-sector neoclassical growth model (Burmeister and Dobell, 1970; Barro and Salai-Martin, 1995). The population consists of officials and workers. Each group is homogenous and the population of each group is fixed. Workers are fully employed by the industrial sector and officials are fully employed by the public sector. Households own assets of the economy and distribute their incomes to consume and save. The industrial sector uses labor and capital inputs to produce goods. Exchanges take place in perfectly competitive markets. Factor markets work well and factors are fully utilized at every moment. Saving is undertaken only by households. Let subscripts $j=1$ and $j=2$ stand for workers and officials respectively. We use $\bar{N}_{j}$ to stand for the fixed population of group $j$. Let $T_{j}(t)$ stand for the work time of a representative household of group $j$ and $N_{j}(t)$ for the flow of services used at time $t$ for production. We have $N_{j}(t)$ as follows

$$
N_{j}(t)=h_{j} \bar{N}_{j} T_{j}(t)
$$

where $h_{j}$ is the fixed level of human capital of group $j$. Here, we assume that officials' work time is also endogenous. It is considered that a rise in income due to wage increase or corruption affects officials' work time.

\section{The industrial sector}

We specify the industrial sector's production function as follows

$$
F(t)=A G^{\theta}(t) K_{i}^{\alpha_{i}}(t) N_{i}^{\beta_{i}}(t), \alpha_{i}+\beta_{i}=1, \quad A, \theta, \alpha_{i}, \beta_{i}>0,
$$


where $A, \theta, \alpha_{i}$ and $\beta_{i}$ are parameters. Different from Chen and Guo (2014) but similar to de Vaal and Ebben (2011), we take account of possible effects of public goods $G(t)$ on productivity. We use $\phi$ to stand for the fixed corruption rate on output level. The tax rate on output $\tau$ is determined by the government. We introduce $\bar{\phi} \equiv 1-\phi-\tau$. Here, we neglect any effect of corruption on firms' capital and labor force. The marginal conditions are

$$
r(t)+\delta_{k}=\frac{\alpha_{i} \bar{\phi} F(t)}{K_{i}(t)}, \quad w_{1}(t)=\frac{\beta_{i} \bar{\phi} F(t)}{N_{1}(t)},
$$

where $r(t)$ is the rate of interest and $w_{1}(t)$ is the worker's wage rate per unit of time.

\section{Workers' disposable income budget constraint}

Let $\bar{k}_{1}(t)$ stand for the wealth owned by a representative work. If there is no corruption on the worker, the current income is $r(t) \bar{k}(t)+w_{1}(t) T_{1}(t)$. The total value of wealth that the representative household can sell to purchase goods and to save is $\bar{k}_{1}(t)$. We assume that selling and buying wealth can be conducted instantaneously without any transaction cost. The disposable income is

$$
\bar{k}_{1}(t)+r(t) \bar{k}_{1}(t)+h_{1} w_{1}(t) T_{1}(t) .
$$

We assume that the corruption rates on wealth and wage rate are respectively $\phi_{k}$ and $\phi_{w}$. After paying the corruption fee to the official, the representative household's disposable income $\hat{y}_{1}$ is

$$
\hat{y}_{1}(t) \equiv \bar{\phi}_{k}(1+r(t)) \bar{k}_{1}(t)+\bar{\phi}_{w} h_{1} w_{1}(t) T_{1}(t)
$$

where $\bar{\phi}_{k} \equiv 1-\phi_{k}$ and $\bar{\phi}_{w} \equiv 1-\phi_{w}$. The worker spends the disposable income on saving $s_{1}(t)$ and consumption $c_{1}(t)$. The budget constraint implies

$$
c_{1}(t)+s_{1}(t)=\hat{y}_{1}(t) \text {. }
$$

This equation means that consumption and savings exhaust the consumers' disposable income. Denote $\bar{T}_{j}(t)$ the leisure time at time $t$ for group $j$ and the (fixed) available time for work and leisure by $T_{0}$. The time constraint for each group is

$$
T_{j}(t)+\bar{T}_{j}(t)=T_{0}, \quad j=1,2 .
$$

Insert (3) and (5) in (4)

$$
c_{1}(t)+s_{1}(t)+\bar{w}_{1}(t) \bar{T}_{1}(t)=\bar{y}_{1}(t) \equiv \bar{\phi}_{k}(1+r(t)) \bar{k}_{1}(t)+\bar{w}_{1}(t) T_{0},
$$

where $\bar{w}_{1}(t) \equiv \bar{\phi}_{w} h_{1} w_{1}(t)$. 


\section{Officials' disposable income and budget constraint}

Let $\bar{k}_{2}(t)$ stand for the capital wealth owned by the representative official. We assume that the representative official's wage income per unit of qualified work time is paid in proportion to the worker's wage rate as follows

$$
\bar{w}_{2}(t)=u_{0} h_{2} w_{1}(t)
$$

where $u_{0}(t)>0$ is determined by the government budget. The official wage rate is proportional to the worker's market wage rate. The representative official receives the total income due to corruption as follows

$$
w_{c}(t) \equiv \frac{\phi F(t)+\phi_{k}(1+r(t)) \bar{k}_{1}(t) \bar{N}_{1}+\phi_{w} h_{1} w_{1}(t) T_{1}(t) \bar{N}_{1}}{\bar{N}_{2}} .
$$

The representative official's disposable income $\hat{y}_{2}$ is

$$
\hat{y}_{2}(t) \equiv(1+r(t)) \bar{k}_{2}(t)+\bar{w}_{2}(t) T_{2}(t)+w_{c}(t) .
$$

The official spends the disposable income on saving $s_{2}(t)$ and consumption $c_{2}(t)$. The budget constraint implies

$$
c_{2}(t)+s_{2}(t)=\hat{y}_{2}(t) .
$$

Insert (9) and (5) in (10)

$$
c_{2}(t)+s_{2}(t)+\bar{w}_{2}(t) \bar{T}_{2}(t)=\bar{y}_{2}(t) \equiv(1+r(t)) \bar{k}_{2}(t)+\bar{w}_{2}(t) T_{0}+w_{c}(t) .
$$

\section{The utility functions and optimal decisions}

The representative household in each group chooses three variables, $c_{j}(t), s_{j}(t)$ and $\bar{T}_{j}(t)$ subject to the budget constraint. The utility level $U_{j}(t)$ is related to the three variables as follows

$$
U_{j}(t)=u_{j}(G(t), t) \bar{T}_{j}^{\sigma_{0 j}}(t) c_{j}^{\xi_{0 j}}(t) s_{j}^{\lambda_{0 j}}(t), \sigma_{0 j}, \xi_{0 j}, \lambda_{0 j}>0
$$

where $u_{j}$ is a time-dependent variable, $\sigma_{0 j}, \xi_{0 j}$ and $\lambda_{0 j}$ are called respectively the worker's/official's propensity to stay at home, the propensities to consume good and to hold wealth. Maximizing $U_{j}$ subject to budget constraint (6)/(11) yields

$$
\bar{w}_{j}(t) \bar{T}_{j}(t)=\sigma_{j} \bar{y}_{j}(t), \quad c_{j}(t)=\xi_{j} \bar{y}_{j}(t), s_{j}(t)=\lambda_{j} \bar{y}_{j}(t)
$$

where

$$
\rho_{j} \equiv \frac{1}{\sigma_{0 j}+\xi_{0 j}+\lambda_{0 j}}, \sigma_{j} \equiv \rho_{j} \sigma_{0 j}, \quad \xi_{j} \equiv \rho_{j} \xi_{0 j}, \lambda_{j} \equiv \rho_{j} \lambda_{0 j}
$$

\section{The wealth accumulation}


According to the definitions of $s_{j}(t)$ and $\bar{k}_{j}(t)$, the change in the household's wealth is given by

$$
\dot{\bar{k}}_{j}(t)=s_{j}(t)-\bar{k}_{j}(t)
$$

This equation simply means that change in the wealth is equal to saving minus dissaving.

\section{The public sector}

The public sector is financially supported by the government's tax income. The public sector's income is $\tau F(t)$. We assume that the service that the public provides is dependent only on the officials' labor input $N_{2}(t)$, described by the following public sector production function

$$
G(t)=A_{p} N_{2}^{\gamma}(t), A_{p}, \gamma>0 .
$$

The government's tax income is $\tau F(t)$. The government's expenditure is $\bar{w}_{2}(t) T_{2}(t) \bar{N}_{2}$. The government budget is

$$
\bar{w}_{2}(t) T_{2}(t) \bar{N}_{2}=\tau F(t) .
$$

For simplicity of analysis we don't introduce possible corruption of the officials on governance and government expenditures. The interaction between corruption and governance may affect the efficiency of public spending, which will influence growth (Dzhumashev, 2014).

\section{Wealth being owned by the households}

The sum of the wealth owned by the two groups is equal to the national capital

$$
\bar{k}_{1}(t) \bar{N}_{1}+\bar{k}_{2}(t) \bar{N}_{2}=K(t) .
$$

\section{The total demand equaling the total supply}

The total demand for the product is equal to the supply

$$
\sum_{j=1}^{2} c_{j}(t) \bar{N}_{j}+\sum_{j=1}^{2} s_{j}(t) \bar{N}_{j}+\delta_{k} K(t)=F(t)+K(t) .
$$

We built the model. The dynamic general equilibrium model describes the interdependence between wealth accumulation of the workers and officials, public good supply, income and wealth distribution, endogenous labor supply, and economic structure with different ways of corruption. The rest of the paper deals with properties of the model.

\section{The behavior of the model}

This section examines properties of the nonlinear dynamic model. We introduce a variable

$$
z(t) \equiv \frac{r(t)+\delta_{k}}{w_{1}(t)}
$$


The following lemma shows that the motion of the entire economic system can be described by two differential equations. The following lemma is checked in the Appendix.

\section{Lemma}

The dynamics of the economic system is governed by the following two differential equations with the tax rate as the variable

$$
\begin{aligned}
& \dot{z}(t)=\tilde{f}_{1}(z(t), G(t)), \\
& \dot{G}(t)=\tilde{f}_{2}(z(t), G(t)),
\end{aligned}
$$

where $\tilde{f}_{j}(t)$ is are functions of $z(t)$ and $G(t)$ defined in the appendix. The values of all the other variables are uniquely determined as functions of $z(t)$ and $G(t)$ at any point in time by the following procedure: $u_{0}(t)$ by (A19) $\rightarrow \bar{k}_{1}(t)$ and $\bar{k}_{2}(t)$ by (A20) $\rightarrow r(t)$ and $w_{1}(t)$ by (A2) $\rightarrow \bar{w}_{2}(t)$ by (7) $\rightarrow w_{c}(t)$ by (A6) $\rightarrow N_{1}(t)$ by (A5) $\rightarrow N_{2}(t)$ by $(\mathrm{A} 13) \rightarrow K(t)$ by $(\mathrm{A} 1) \rightarrow \bar{y}_{j}(t)$ by $(\mathrm{A} 8) \rightarrow F(t)$ by (A3) $\rightarrow c_{j}(t), s_{j}(t)$, and $\bar{T}_{j}(t)$ by (12) $\rightarrow$ $N_{2}(t)=h_{2} \bar{N}_{2} T_{2}(t)$.

As the expressions are tedious, it is difficult to interpret the analytical results. For illustration, we simulate the model to demonstrate dynamic properties of the model. We specify the parameter values as follows

$$
\begin{aligned}
\bar{N}_{1} & =100, \quad \bar{N}_{2}=10, T_{0}=24, \quad h_{1}=2.5, \quad h_{2}=2.5, \quad \alpha_{i}=0.3, A=1.2, A_{p}=0.9, \\
\xi_{01} & =0.15, \lambda_{01}=0.4, \sigma_{01}=0.3, \quad \xi_{02}=0.15, \quad \lambda_{02}=0.5, \quad \sigma_{02}=0.15, \quad \theta=0.1, \quad \gamma=0.3 \\
\tau & =0.01, \phi=0.03, \phi_{k}=0.05, \quad \phi_{w}=0.05, \quad \delta_{k}=0.05 .
\end{aligned}
$$

The ratio between the number of the workers and the number of the officials is $10: 1$. The representative worker's relative propensity to save and the official's relative propensity to save are respectively

$$
\lambda_{1}=\frac{0.4}{0.4+0.3+0.15}=\frac{8}{17}<\lambda_{2}=\frac{0.5}{0.5+0.15+0.15}=\frac{5}{8} .
$$

The official's propensity to save is higher than the worker's propensity to save. Intuitively this implies that in this neoclassical growth model corruption may benefit economic growth as the wealth is shifted from the group with the lower propensity to save to the group with higher propensity to save. The two groups have the same level of human capital. The tax rate is fixed at one percent. We specify the initial conditions as follows

$$
z(0)=0.21, G(0)=2.4 \text {. }
$$

The changes of the variables over time are plotted in Figure 1. The workers supply more labor and the officials work less over time. The national product and wealth rise. The rate of interest falls. The wage rates and wage incomes are enhanced. 

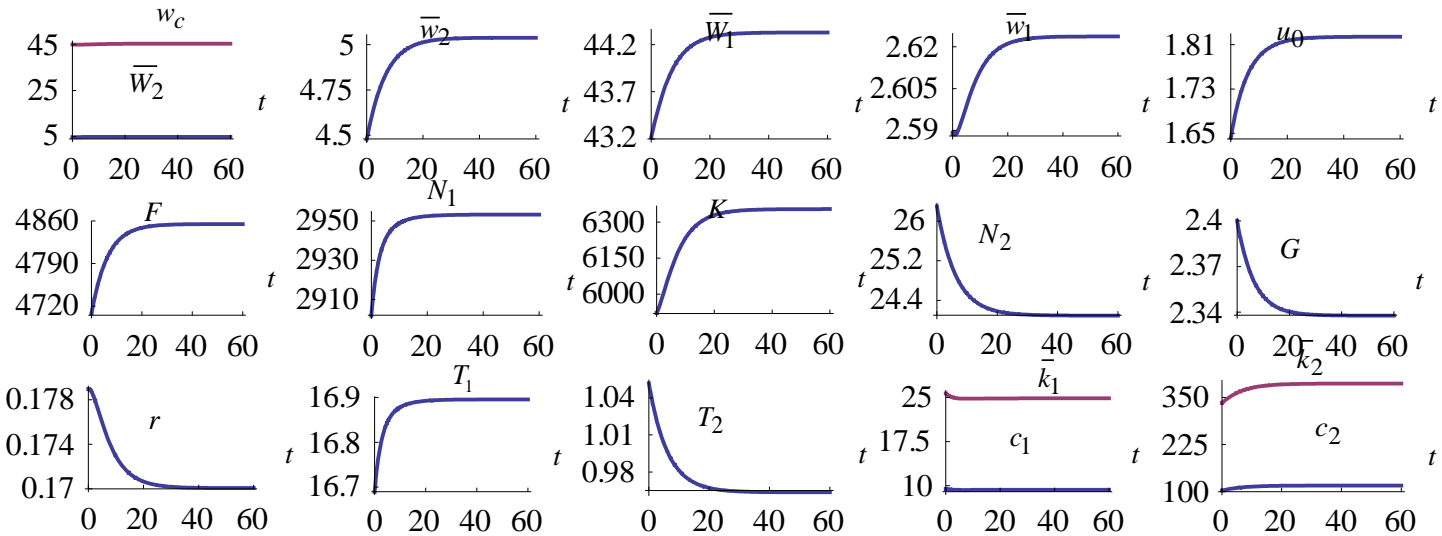

\section{Figure}

1.

The

Motion

of

the

System

The equilibrium values of the variables are given as follows

$$
\begin{gathered}
u_{0}=1.82, \quad w_{c}=45.4, \quad w_{1}=1.12, \bar{w}_{2}=5, \bar{W}_{1}=44.3, \bar{W}_{2}=4.86, N_{1}=2953.3, \\
N_{2}=24.1, \quad \bar{K}_{1}=2485.4, \bar{K}_{2}=3868.8, \quad F=4855, \quad G=2.34, \bar{k}_{1}=24.9, \\
\bar{k}_{2}=386.9, \quad T_{1}=16.9, \quad \bar{T}_{1}=7.1, T_{2}=1, \bar{T}_{2}=23, \quad c_{1}=9.3, \quad c_{2}=116,
\end{gathered}
$$

where $\bar{W}_{j}=\bar{w}_{j} T_{j}$. The eigenvalues are

$$
-0.425,-0.16 \text {. }
$$

The equilibrium point is stable. This result is important as it allows us to effectively conduct comparative dynamic analysis.

\section{Comparative Dynamic Analysis}

The previous section plotted the motion of the economic system with the initial condition. This section shows how a change in any parameter alters the motion of the system. As the system is stable and we can plot the motion of the system, we can effectively conduct comparative dynamic analysis. We use the variable, $\bar{\Delta} x(t)$, to represent the change rate of the variable, $x(t)$, in percentage due to changes in the parameter value.

\section{A rise of the corruption rate on the output level}

We first study how the economic system is affected when the corruption rate on the output level is increased as follows: $\phi: 0.03 \Rightarrow 0.035$, where " $\Rightarrow$ " stands for "being changed to". The output falls initially and rises in the long term. As the corruption rate is increased, the ratio between the actual wage and the market wage rises. The official's wage rate per unit time 
$\bar{w}_{2}$, wage income $\bar{W}_{2}$, and corrupt income $w_{c}$, are increased. The worker's wage rate per unit time $\bar{w}_{1}$ and wage income $\bar{W}_{1}$ are reduced. The official works less and the public supply falls. The official consumes less and has less wealth initially and consumes more and has more wealth in the long term. The representative worker consumes less. The work has more wealth initially and less wealth in the long term. In the long term the worker works longer hours and the nation has more capital. As the wealth accumulated to the corrupt official is partly saved, the national capital is increased. The rate of interest is reduced. The long-term impact is the national economic growth.
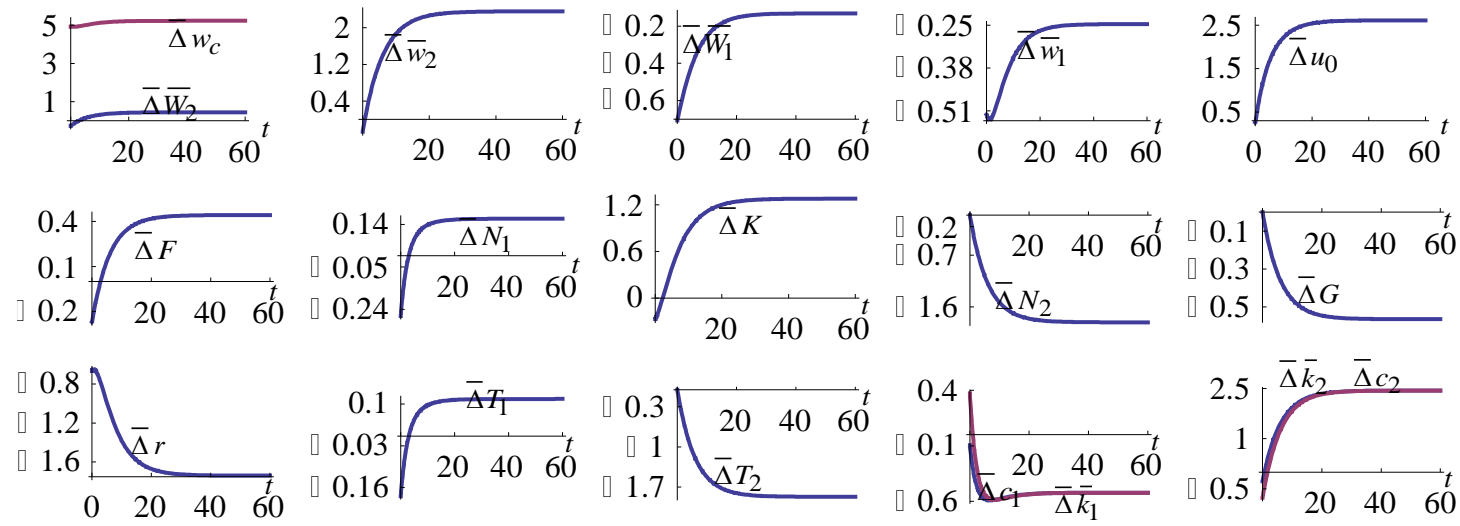

Figure 2. A Rise of the Corruption Rate on the Output Level

\section{A rise of the corruption rate on the capital income}

We now allow the corruption rate on the capital income to be increased as follows: $\phi_{k}: 0.05 \Rightarrow 0.07$. The long-term effects of the change in the corruption rate on the capital income are similar to the effects of the change in the corruption rate on the output level. The country's output is increased. The officials have more wealth and consume more. The workers have less wealth and consume more.
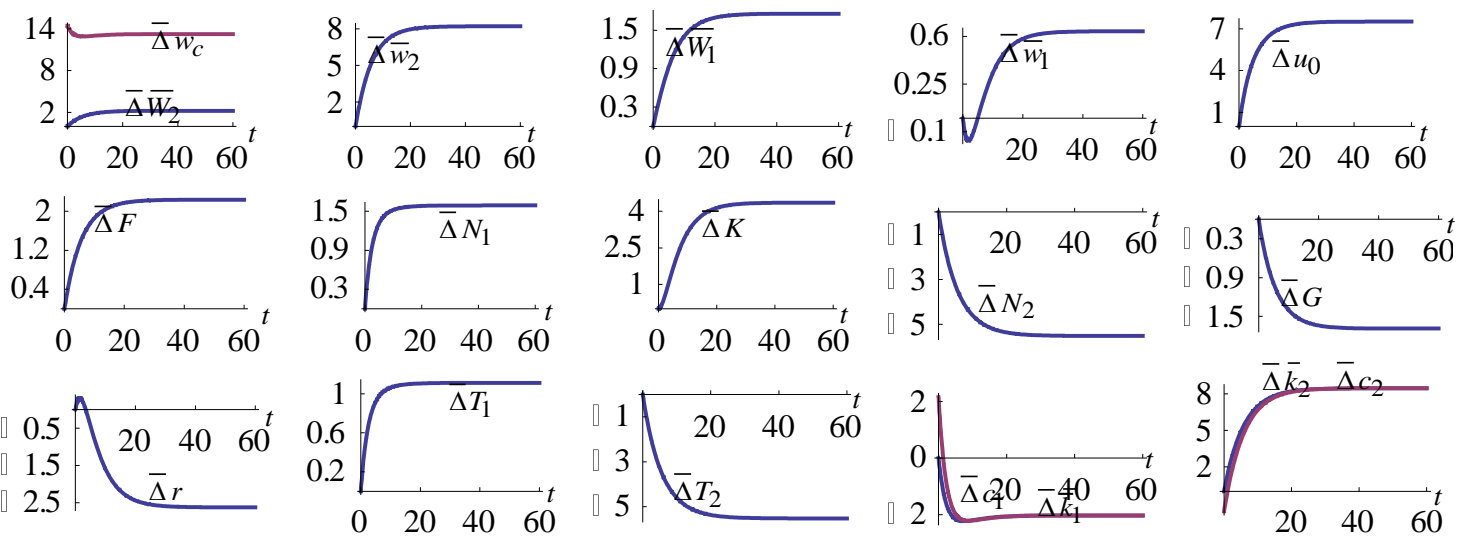

Figure 3. A Rise of the Corruption Rate on the Capital Income 


\section{A rise of the corruption rate on the wage income}

The corruption rate on the wage income is increased as follows: $\phi_{w}: 0.05 \Rightarrow 0.07$. The long-term effects of the change in the corruption rate on the wage income are similar to the effects of the change in the corruption rate on the output level. The country's output is increased. The officials have more wealth and consume more. The workers have less wealth and consume more. It should be noted that when the corruption rate on the capital income is increased, the worker's wage rate and wage income are increased; when the corruption rate on the wage income is increased, the worker's wage rate and wage income are reduced.
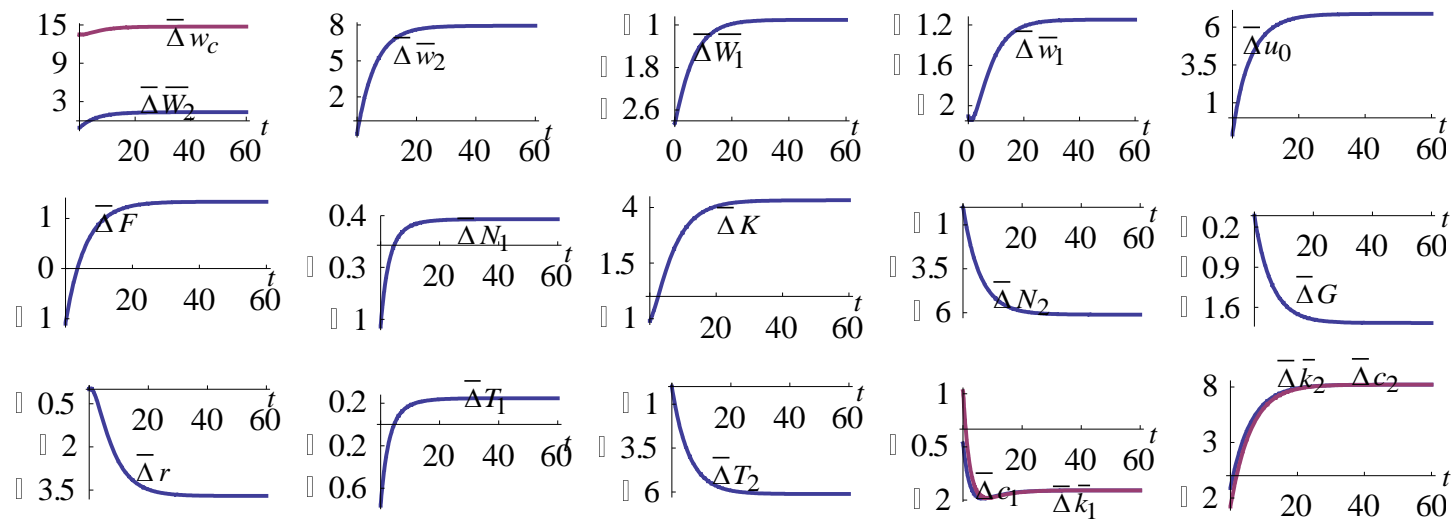

Figure 4. A Rise of the Corruption Rate on the Wage Income

\section{A rise of the officials' human capital}

We now increase the officials' human capital as: $h_{2}: 2.5 \Rightarrow 2.6$. The national output is increased over time. The national output increase is mainly due to the rise in the public service. The rise in the public service is due to the human capital improvement. The ratio between the official's actual wage and the market wage rises initially and falls in the long term. The official's wage rate per unit time $\bar{w}_{2}$ and wage income $\bar{W}_{2}$ are increased. The corrupt income $w_{c}$ falls initially and rises in the long term. The worker's wage rate per unit time $\bar{w}_{1}$ and wage income $\bar{W}_{1}$ are also increased. The official works less hours initially and almost the same hours in the long term. The worker works more hours initially and almost the same hours in the long term. The official supplies more labor and produces more public service. The worker's consumption level and wealth fall initially and rise in the long term. The official's consumption level and wealth fall initially and rise in the long term. 

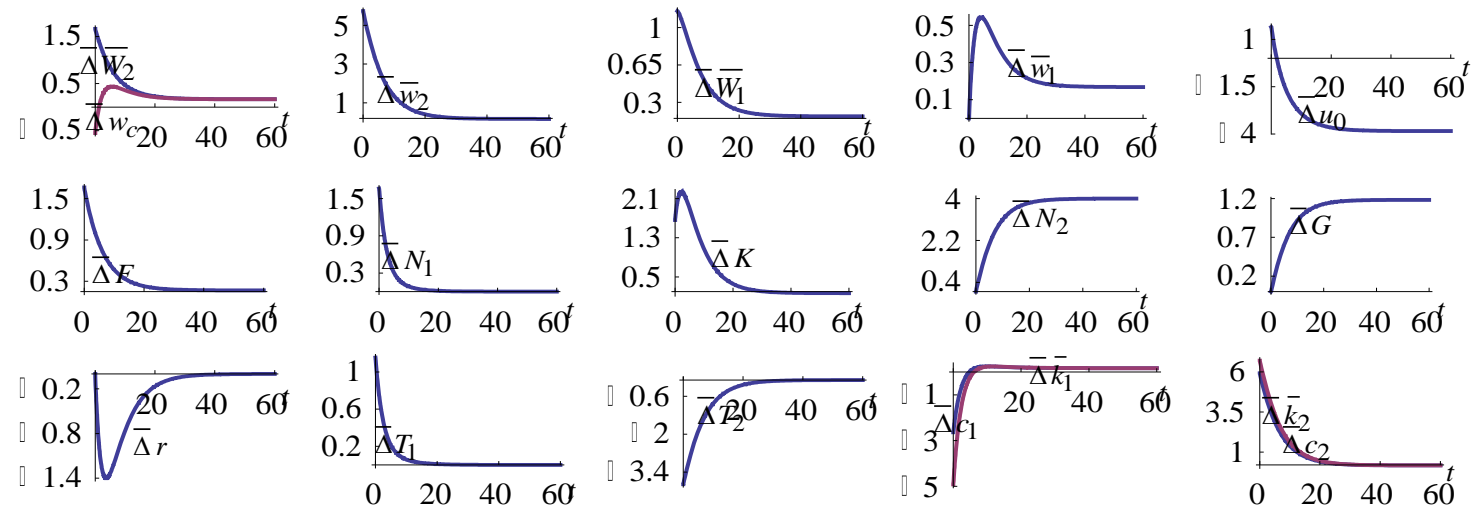

Figure 5. A Rise of the Officials' Human Capital

\section{A rise of the officials' propensity to save}

Officials might not show their consumption of luxuries and try to save their income, for instance, due to political environment changes. Economically this implies that the officials' propensity to save is enhanced. We now consider the following rise in the officials' propensity to save: $\lambda_{2}: 0.5 \Rightarrow 0.52$. The national output is increased over time. The national output increase is mainly due to the rise in the national capital service. The rise in the national wealth comes from the enhanced propensity to save. The officials work less hours and the total official labor supply is reduced. The public service supply falls. The official's wage rate per unit time and wage income are increased. The corrupt income $w_{c}$ falls initially and rises in the long term. The worker's consumption level and wealth fall initially and rise in the long term. The official's consumption level and wealth rise in the long term.
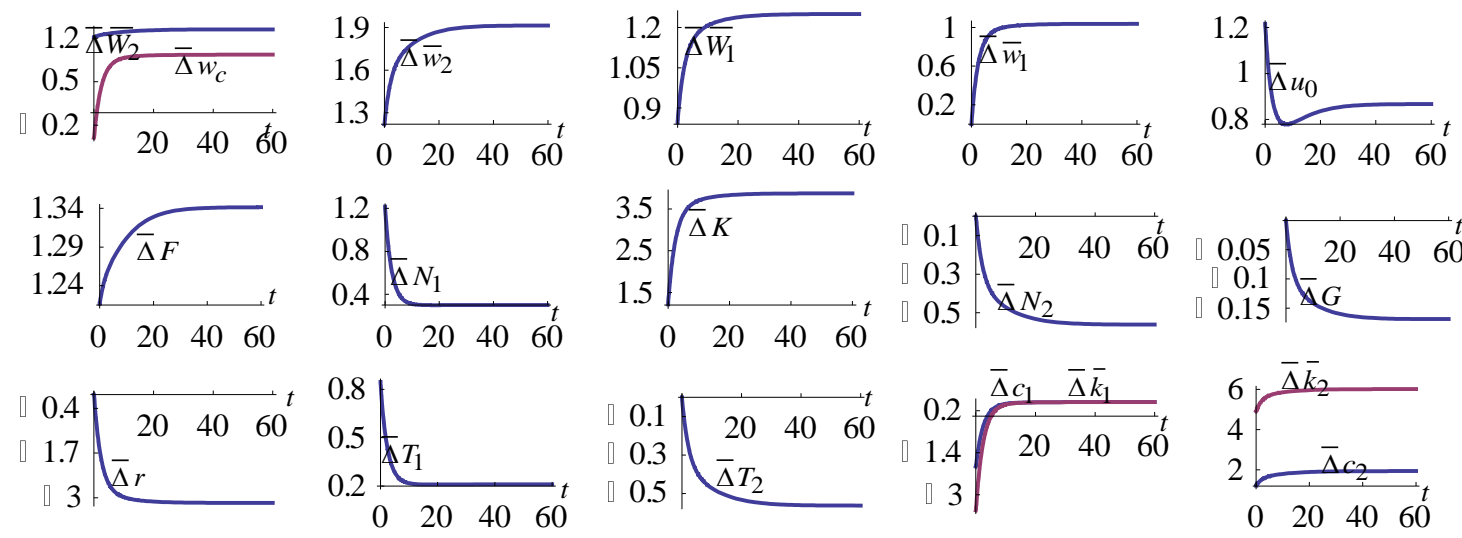

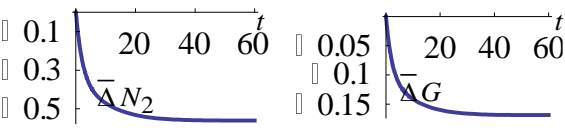

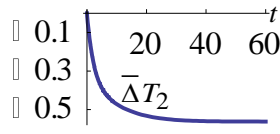

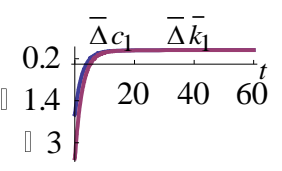

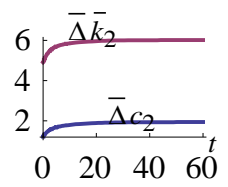

Figure 6. A Rise of the Officials' Propensity to Save

\section{A rise of the number of the officials}

We fix the total population. We now consider that the share of officials in the population is increased. The expansion of the public sector may be due to different reasons. We now consider the following shift of the labor force structure 


$$
\bar{N}_{1}: 100 \Rightarrow 99.5, \quad \bar{N}_{2}: 10 \Rightarrow 10.5 .
$$

The ratio between the official's actual wage and the market wage rises initially and falls in the long term. The corrupt income per official $w_{c}$ falls. The official's wage rate per unit time and wage income are reduced. The worker's wage rate per unit time and wage income are increased. The worker's working time rises initially and changes slightly in the long term. The official's working time falls. The worker's consumption level and wealth fall initially and rise slightly in the long term. The official's consumption level and wealth rise initially and fall in the long term. The workers' total labor supply rise initially and fall in the long term. The officials' total labor supply rise and public service is increased. It should be noted that in the literature of corruption and growth there are opposite conclusions. One argument is that a rise in the government size may produce more opportunities for corruption (e.g., Goel and Nelson, 1998; Rose-Ackerman, 1999; Alesina and Angeletos, 2005). The other argument is that an enlarged government sector may strengthen control of corruption and thus encourage economic growth (Billger and Goel, 2009). Our study shows that the two effects exist - in the short term economic growth is encouraged but in the long-term economic growth is discouraged.
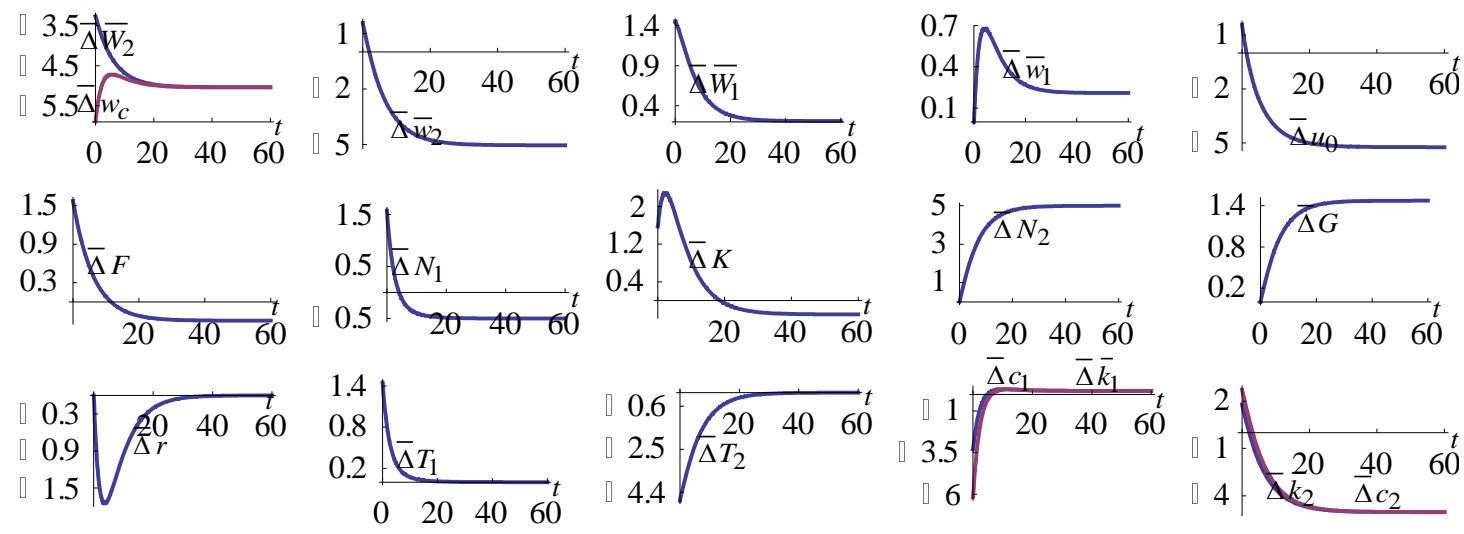

Figure 7. A Rise of the Number of the Officials

\section{A rise of the workers' human capital}

The government tens to encourage workers' human capital, for instance, through subsiding education and providing differential education programs. We now allow the workers' human capital to be changed as follows: $h_{1}: 2.5 \Rightarrow 2.6$. The ratio between the official's actual wage and the market wage is enlarged. The corrupt income per official rises. The official's wage rate per unit time and wage income are increased. The official works less hours. The officials' total labor supply falls and public service is reduced. The official's consumption level and wealth are increased. The official class benefits. The worker's wage rate per unit time and wage income are increased. The worker's working time is increased. The worker's consumption level and wealth rise initially and fall in the long term. The workers' total labor supply rise. The national wealth and output are increased. The rate of interest rises. We see that the worker class does not benefit in the long term. 

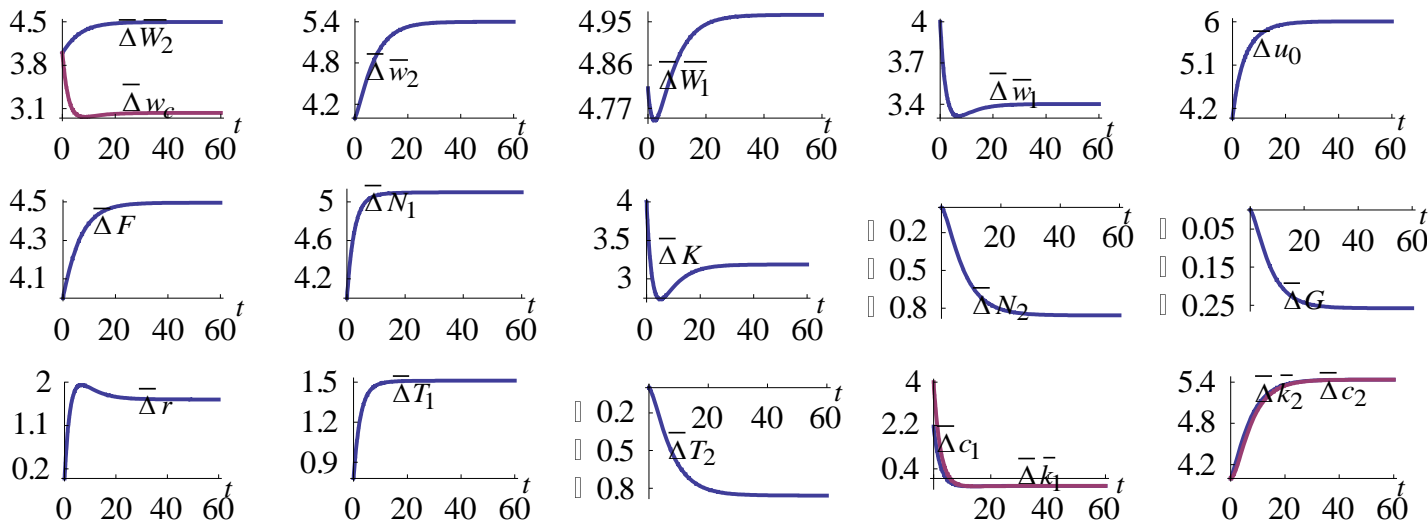

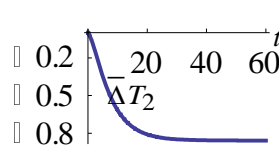

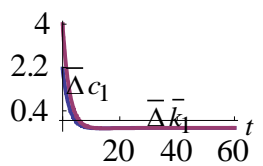

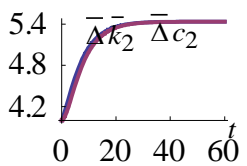

\section{Figure 8. A Rise of the Workers' Human Capital}

\section{Concluding Remarks}

This study developed a dynamic general equilibrium model with endogenous wealth and corruption. The economy is composed of one (private) production sector and one public sector. The public service sector is carried out by officials. Its cost is financially supported by taxation on the private sector. Its output affects the private sector's productivity and the people's welfare. The production sector employs the workers' labor inputs and capital. The population is classified into workers and officials. We assume that officials are corrupt in the sense that they take bribes from the private sector and households. The corruption is measured by the corruption rates on the output level of the private sector, the wealth interest returns of the workers, and the wage income of the workers. We simulated the model and examined the transitory and long-run effects of changes in some parameters. The comparative dynamic analysis provided insights into the complicated impact of corruption on economic growth process. For instance, if the workers' human capital is enhanced, then (i) the ratio between the official's actual wage and the market wage is enlarged; (ii) the corrupt income per official rises; (iii) the official's wage rate per unit time and wage income are increased; (iv) the official works less hours and public service is reduced; (v) the official's consumption level and wealth are increased; (vi) the worker's consumption level and wealth rise initially and fall in the long term; (vii) the workers' total labor supply rise, the national wealth and output are increased; and (viii) the official class benefits and the worker class loses in the long term. The enhanced human capital by the workers will not benefit themselves in the long term, even though they benefit in the short term. As mentioned before, although there is a vast literature on corruption, there are relatively few macroeconomic growth models with endogenous wealth in a dynamic general equilibrium framework. Hence, our model can be generalized and extended in different ways. For instance, there are many other possible channels of corruption. We may also introduce institutional structure to allow corruption networks. The workers are not homogenous and the officials are heterogeneous in regard to morality, position and human capital. In an economic system with endogenous knowledge, corruption may not encourage innovative activities as innovators need government's support (e.g., Mo, 2001).

\section{Appendix: Proving the Lemma}

From (2) we have

$$
z \equiv \frac{r+\delta_{k}}{w_{1}}=\frac{N_{1}}{\bar{\beta}_{i} K},
$$

where $\bar{\beta}_{i} \equiv \beta_{i} / \alpha_{i}$. From (A1), (1) and (2), we have 


$$
r(z, G)=A_{r} \bar{\phi}-\delta_{k}, w_{1}(z, G)=A_{w} \bar{\phi},
$$

where

$$
A_{r}(z, G)=\alpha_{i} A \bar{\beta}_{i}^{\beta_{i}} G^{\theta} z^{\beta_{i}}, A_{w}(z, G)=\frac{\beta_{i} A G^{\theta} z^{-\alpha_{i}}}{\bar{\beta}_{i}^{\alpha_{i}}} .
$$

Equations

and

imply

$$
F=N_{1} f,
$$

where $f \equiv A G^{\theta} / \bar{\beta}_{i}^{\alpha_{i}} z^{\alpha_{i}}$. From (12) we have

$$
\bar{T}_{1}=\sigma_{1} T_{0}+\frac{\sigma_{1} \bar{\phi}_{k}(1+r) \bar{k}_{1}}{\bar{w}_{1}} \text {. }
$$

From the definition of $N_{1},(\mathrm{~A} 4)$ and (5) we get

$$
N_{1}=n_{0}-n \bar{k}_{1},
$$

where

$$
n_{0} \equiv\left(1-\sigma_{1}\right) h_{1} \bar{N}_{1} T_{0}, n \equiv \frac{\sigma_{1} h_{1} \bar{N}_{1} \bar{\phi}_{k}(1+r)}{\bar{w}_{1}} .
$$

From (8) and (A3) we have

$$
w_{c}=q_{z} N_{1}+q_{k} \bar{k}_{1}+q_{0},
$$

where we also use and

and

$q_{z} \equiv \frac{\phi f}{\bar{N}_{2}}, \phi_{0} \equiv \frac{\phi_{w} \sigma_{1} \bar{N}_{1}}{\bar{\phi}_{w}}, q_{k} \equiv \frac{\left(\phi_{k} \bar{N}_{1}-\phi_{0} \bar{\phi}_{k}\right)(1+r)}{\bar{N}_{2}}, q_{0} \equiv \frac{\phi_{w} h_{1} w_{1} T_{0} \bar{N}_{1}-\phi_{0} \bar{w}_{1} T_{0}}{\bar{N}_{2}}$.

From (18), (17) and (A1) we have

$$
\bar{k}_{1} \bar{N}_{1}+\bar{k}_{2} \bar{N}_{2}=\frac{N_{1}}{z \bar{\beta}_{i}} .
$$

Insert (A5) in (A7) 


$$
\bar{k}_{1}=\frac{\tilde{n}_{0} n_{0}}{z \bar{\beta}_{i}}-\bar{k}_{2} \tilde{n}_{0} \bar{N}_{2}
$$

where

$$
\tilde{n}_{0}=\left(\bar{N}_{1}+\frac{n}{z \bar{\beta}_{i}}\right)^{-1}
$$

From (6), (11) and (A6) we have

$$
\begin{aligned}
& \bar{y}_{1}=\bar{\phi}_{k}(1+r) \bar{k}_{1}+\bar{\phi}_{w} w_{1} T_{0}, \\
& \bar{y}_{2}=(1+r) \bar{k}_{2}+\bar{w}_{2} T_{0}+q_{z} N_{1}+q_{k} \bar{k}_{1}+q_{0} .
\end{aligned}
$$

From (12) and the time constraint we have

$$
T_{2}=T_{0}-\frac{\sigma_{2} \bar{y}_{2}}{\bar{w}_{2}}
$$

Insert (A9) in (A10

$$
T_{2}=\left(1-\sigma_{2}\right) T_{0}-\sigma_{2}\left(\frac{(1+r) \bar{k}_{2}+q_{z} N_{1}+q_{k} \bar{k}_{1}+q_{0}}{\bar{w}_{2}}\right) .
$$

Insert (A5) and (A11) in $N_{2}=h_{2} \bar{N}_{2} T_{2}$

$$
N_{2}=\tilde{n}-\bar{n} \bar{k}_{1}-\frac{(1+r) h_{2} \bar{N}_{2} \sigma_{2} \bar{k}_{2}}{\bar{w}_{2}},
$$

where

$$
\tilde{n}=\sigma_{2} h_{2} \bar{N}_{2}\left(\left(\frac{1}{\sigma_{2}}-1\right) T_{0}-\frac{q_{z} n_{0}+q_{0}}{\bar{w}_{2}}\right), \bar{n}=\sigma_{2} h_{2} \bar{N}_{2}\left(\frac{q_{k}-n q_{z}}{\bar{w}_{2}}\right) .
$$

Insert (A8) in (A12)

$$
N_{2}=\hat{n}_{0}+\hat{n} \bar{k}_{2} \text {, }
$$

where 


$$
\hat{n}_{0} \equiv \tilde{n}-\frac{\tilde{n}_{0} \bar{n} n_{0}}{z \bar{\beta}_{i}}, \hat{n} \equiv \bar{n} \tilde{n}_{0} \bar{N}_{2}-\frac{(1+r) h_{2} \bar{N}_{2} \sigma_{2}}{\bar{w}_{2}} .
$$

From (14) and (A13) we have

$$
\bar{k}_{2}=f_{2}\left(z, G, u_{0}\right) \equiv\left(\frac{G}{A_{p}}\right)^{1 / \gamma} \frac{1}{\hat{n}}-\frac{\hat{n}_{0}}{\hat{n}} .
$$

Insert (A14) in (A8)

$$
\bar{k}_{1}=f_{1}\left(z, G, u_{0}\right) \equiv \frac{\tilde{n}_{0} n_{0}}{z \bar{\beta}_{i}}-f_{2} \tilde{n}_{0} \bar{N}_{2} .
$$

From (15) and (A3) we have

$$
\left(\frac{1}{\sigma_{2}}-1\right) T_{0} \bar{w}_{2}-(1+r) \bar{k}_{2}-\hat{q}_{k} \bar{k}_{1}=f_{0},
$$

where we also (A11) and

$$
f_{0} \equiv q_{0}+\left(\frac{\tau f}{\sigma_{2} \bar{N}_{2}}+q_{z}\right) n_{0}, \quad \hat{q}_{k} \equiv q_{k}-\left(\frac{\tau f}{\sigma_{2} \bar{N}_{2}}+q_{z}\right) n .
$$

Insert (A8) in (A16)

$$
\bar{w}_{2}-\tilde{f}_{0} \bar{k}_{2}=\hat{f}_{0},
$$

where

$$
\begin{aligned}
& \tilde{f}_{0}\left(z, G, u_{0}\right) \equiv\left((1+r)-\hat{q}_{k} \tilde{n}_{0} \bar{N}_{2}\right) t_{2}, \\
& \hat{f}_{0}\left(z, G, u_{0}\right) \equiv\left(\frac{\hat{q}_{k} \tilde{n}_{0} n_{0}}{z \bar{\beta}_{i}}+f_{0}\right) t_{2}, t_{2} \equiv\left(\frac{1}{\sigma_{2}}-1\right)^{-1} \frac{1}{T_{0}}
\end{aligned}
$$

Insert (A14) in (A17)

$$
m_{0} \bar{w}_{2}+\frac{\tilde{f}_{0} \tilde{n} \bar{w}_{2}}{\sigma_{2} h_{2} \bar{N}_{2}}=m_{1},
$$

where we also use the definitions of $\hat{n}$ and 


$$
\begin{aligned}
& m_{0}(z, G) \equiv\left(q_{k}-n q_{z}\right) \tilde{n}_{0} \bar{N}_{2}-(1+r)-\frac{\tilde{f}_{0}}{\sigma_{2} h_{2} \bar{N}_{2}}\left(\frac{G}{A_{p}}\right)^{1 / \gamma} \\
& m_{1}(z, G) \equiv\left(\frac{\tilde{f}_{0} n_{0}}{z \bar{\beta}_{i}}+\bar{N}_{2} \hat{f}_{0}\right)\left(q_{k}-n q_{z}\right) \tilde{n}_{0}-(1+r) \hat{f}_{0}
\end{aligned}
$$

Inserting the definition of $\tilde{n}$ in (A18), we have

$$
u_{0}(z, G)=\left(\left(q_{z} n_{0}+q_{0}\right) \tilde{f}_{0}+m_{1}\right)\left(m_{0}+\frac{\tilde{f}_{0}}{t_{2}}\right)^{-1} \frac{1}{h_{2} w_{1}},
$$

where we use (7). Insert (A19) in (A14) and (A15)

$$
\bar{k}_{j}=f_{j}(z, G) .
$$

We show now that all the variables can be expressed as functions of $z$ and $G$ as follows: $u_{0}$ by (A19) $\rightarrow \bar{k}_{1}$ and $\bar{k}_{2}$ by $(\mathrm{A} 20) \rightarrow r$ and $w_{1}$ by (A2) $\rightarrow \bar{w}_{2}$ by $(7) \rightarrow w_{c}$ by (A6) $\rightarrow N_{1}$ by (A5) $\rightarrow N_{2}$ by (A13) $\rightarrow K$ by (A1) $\rightarrow \bar{y}_{j}$ by (A8) $\rightarrow F$ by (A3) $\rightarrow c_{j}, s_{j}$, and $\bar{T}_{j}$ by (12) $\rightarrow N_{2}=h_{2} \bar{N}_{2} T_{2}$. Take derivatives of (A20) with respect to $t$

$$
\dot{\bar{k}}_{j}=\frac{\partial f_{j}}{\partial z} \dot{z}+\frac{\partial f_{j}}{\partial G} \dot{G}, \quad j=1,2 \text {. }
$$

From the above procedure and (13), we have

$$
\dot{\bar{k}}_{j}=\bar{f}_{j}(z, G) \equiv s_{j}-\bar{k}_{j} .
$$

Insert (A22) in (A21)

$$
\frac{\partial f_{j}}{\partial z} \dot{z}+\frac{\partial f_{j}}{\partial G} \dot{G}=\bar{f}_{j}, \quad j=1,2 .
$$

Solve (A23)

$$
\begin{aligned}
& \dot{z}=\tilde{f}_{1}(z, G), \\
& \dot{G}=\tilde{f}_{2}(z, G) .
\end{aligned}
$$

We thus proved the lemma.

\section{References}

[1] Agénor, P.-R. (2011) Schooling and Public Capital in a Model of Endogenous Growth. Economica 78, 108-132. 
[2] Aghion, P., Akcigit, U., Cage, J., and Kerr, W.R. (2016) Taxation, Corruption, and Growth. European Economic Review 86(1), 24-51.

[3] Alesina, A. and Angeletos, G.M. (2005) Corruption, Inequality, and Fairness. Journal of Monetary Economics 52(7), $1227-44$.

[4] Baier, S.L. and Glomm, G. (2001) Long-run Growth and Welfare Effects of Public Policies with Distortionary Taxation. Journal of Economic Dynamics and Control 25, 2007-42.

[5] Barro, R.J. (1990) Government Spending in a Simple Model of Endogenous Growth. Journal of Political Economy 98, S103-25.

[6] Barro, R.J. and X. Sala-i-Martin (1995) Economic Growth. New York: McGraw-Hill, Inc.

[7] Becker, G. (1968) Crime and Punishment: An Economic Approach. Journal of Political Economy 76, 169-217.

[8] Billger, S.M. and Goel, R.K. (2009) Do Existing Corruption Levels Matter in Controlling Corruption? Cross-Country Quantile Regression Estimates. Journal of Development Economics 90(2), 299-305.

[9] Burmeister, E. and Dobell, A.R. (1970) Mathematical Theories of Economic Growth. London: Collier Macmillan Publishers.

[10] Chea, C.C. (2015) Empirical Studies: Corruption and Economic Growth. American Journal of Economics 5(2), 18388.

[11] Chen, S.H. and Guo, J.T. (2014) Progressive Taxation and Macroeconomic (In)stability with Utility-Generating Government Spending. Journal of Macroeconomics 42, 174-83.

[12] D’Agostino, G., Dunne, P., and Pieroni, L. (2016) Government Spending, Corruption and Economic Growth. World Development 84(C), 190-205.

[13] De Vaal, A. and Ebben, W. (2011) Institutions and the Relation between Corruption and Economic Growth. Review of Development Economics 15(1), 108-23.

[14] Del Monte, A. and Papagni, E. (2001) Public Expenditure, Corruption, and Economic Growth: The Case of Italy. European Journal of Political Economy 17(1), 1-16.

[15] Dzhumashev, R. (2014) Corruption and Growth: The Role of Governance, Public Spending, and Economic Development. Economic Modelling 37(C), 201-15.

[16] Ehrlich, I. and Lui, F.T. (1999) Bureaucratic Corruption and Endogenous Economic Growth. Journal of Political Economy 107(6), S270-S293.

[17] Futagami, K., Morita, Y., and Shibata, A. (1993) Dynamic Analysis of an Endogenous Growth Model with Public Capital. Scandinavia Journal of Economics 95, 607-25.

[18] Glaeser, E. and Saks, R. (2006) Corruption in America. Journal of Public Economics 90(6-7), 1053-72.

[19] Glomm, G. and Ravikumar, B. (1997) Productive Government Expenditures and Long-run Growth. Journal of Economic Dynamics and Control 21, 183-204.

[20] Goel, R.K. and Nelson, M.A. (1998) Corruption and Government Size: A Disaggregated Analysis. Public Choice 97, 107-20.

[21] Greiner, A. (2007) An Endogenous Growth Model with Public Capital and Sustainable Government Debt. Japanese Economic Review 58, 345-61.

[22] Gyimah-Brempong, K. (2002) Corruption, Economic Growth and Income Inequality in Africa. Economics and Government 3(3), 183-209.

[23] Hu, Y., Ohdoi, R. and Shimomura, K. (2008) Indeterminacy in a Two-Sector Endogenous Growth Model with Productive Government Spending. Journal of Macroeconomics 30, 1104-23.

[24] Kamiguchi, A. and Tamai, T. (2011) Can Productive Government Spending be a Source of Equilibrium Indeterminacy? Economic Modelling 28, 1335-40.

[25] Leff, N.H. (1964) Economic Development Through Bureaucratic Corruption. The American Behavioral Scientist 8(3), 8-14.

[26] Lin, S.L. and Zhang, W. (2009) The Effect of Corruption on Capital Accumulation. Journal of Economics 97(1), 67-93. 
[27] Lui, F.T. (1996) Three Aspects of Corruption. Contemporary Economic Policy 14(3), $26-29$.

[28] Mauro, P. (1995) Corruption and Growth. Quarterly Journal of Economics 110(3), 681-712.

[29] Mauro, P. (1998) Corruption and the Composition of Government Expenditure. Journal of Public Economics 69(2), 263-79.

[30] Mo, P.H. (2001) Corruption and Economic Growth. Journal of Comparative Economics 29(1), 66-79.

[31] Myrdal, G. (1968) Asian Drama. New York: Random House.

[32] Palivos, T., Yip, C.Y., and Zhang, J. (2003) Transitional Dynamics and Indeterminacy of Equilibria in an Endogenous Growth Model with a Public Input. Review of Development Economics 7, 86-98.

[33] Rivera-Batiz, F.L. (2001) International Financial Liberalization, Corruption, and Economic Growth. Review of International Economics 9(4), 727-737.

[34] Rose-Ackerman, S. (1999) Corruption and Government: Causes, Consequences, and Reform. Cambridge: Cambridge University Press.

[35] Shi, S.Y. and Temzelides, T. (2004) A Model of Bureaucracy and Corruption. International Economic Review 45(3), 873-906.

[36] Swaleheen, M. and Stansel, D. (2007) Economic Freedom, Corruption and Growth. Cato Journal 27(3), 343-58.

[37] Teles, V.K. (2007) Institutional Quality and Endogenous Economic Growth. Journal of Economic Studies 34(1), 2941.

[38] Turnovsky, S.J. (2000) Fiscal Policy, Elastic Labor Supply, and Endogenous Growth. Journal of Monetary Economics 45, 185-210.

[39] Turnovsky, S.J. (2004) The Transitional Dynamics of Fiscal Policy: Long-Run Capital Accumulation and Growth. Journal of Money, Credit, and Banking 36, 883-910.

[40] Zhang, W.B. (1993) Woman's Labor Participation and Economic Growth - Creativity, Knowledge Utilization and Family Preference. Economics Letters 42, 105-110.

[41] Zhang, W.B. (2009) Monetary Growth Theory: Money, Interest, Prices, Capital, Knowledge, and Economic Structure over Time and Space. London: Routledge.

[42] Zhang, W.B. (2010) Economic Growth with Endogenous Labor Supply and Public Good. Global Review of Business and Economic Research 8 (2), 253-72. 
